\title{
Experiences of Therapeutic Hypothermia Therapy on Six Cases with Persistent: Pulmonary Hypertension and Moderate to Severe Hypoxic Ischemic Encephalopathy using Inhaled Nitric Oxide Therapy
}

\author{
Keisuke Kobata*, Makoto Nabetani, Nanae Yutaka, Hiroyuki and Sanno
}

Department of Pediatrics, Yodogawa Christian Hospital Pediatrics, Japan

*Corresponding author: Keisuke Kobata, Department of Pediatrics, Yodogawa Christian Hospital Pediatrics, Japan, Tel: +8166322225; E-mail: a103111@ych.or.jp Rec date: September 03, 2015; Acc date: September 18, 2015; Pub date: September 25, 2015

Copyright: (c) 2015 Kobata K. This is an open-access article distributed under the terms of the Creative Commons Attribution License, which permits unrestricted use, distribution, and reproduction in any medium, provided the original author and source are credited.

\begin{abstract}
We experienced six cases who could undergo therapeutic hypothermia (TH) therapy combined with inhaled nitric oxide (iNO) therapy and one persistent pulmonary hypertension (PPHN) case who could undergo and stop TH during 2002-2014. We experienced no complication in these six cases. We have compared perinatal factors, MRI findings around one-year-old, Gross Motor Function Classification System (GMFCS) and developmental quotient around one and a half year old between 6 cases who underwent TH therapy completely combined with iNO therapy ( $\mathrm{TH}+\mathrm{iNO}$ group) and 38 cases who underwent only TH therapy (TH group). There are no significant differences of perinatal factors, MRI findings, GMFCS, and developmental quotient between (TH+iNO group) and (TH group). These results showed TH could be performed safely for HIE cases with PPHN combined with iNO therapy maintaining the stable condition of respiration and circulation. We need to investigate more PPHN cases with iNO therapy to clarify criteria which cases could be performed TH therapy safely.
\end{abstract}

Keywords Perinatal; Hypertension; Newborn; Infants; Hemorrhage; Gestational -age; Respiratory

\section{Introduction}

International Liaison Committee on Resuscitation (ILCOR) and International Consensus Conference on Cardiopulmonary Resuscitation and Emergency Cardiovascular Care Science With Treatment Recommendations (CoSTR) documented the new guideline that new-borns with moderate to severe hypoxic ischemic encephalopathy (HIE) should be considered for therapeutic hypothermia (TH) in 2010 [1]. Since then, many institutions have started using standardized protocol of $\mathrm{TH}$ in this new guideline all over Japan. On the other hand, many institutions give up to start $\mathrm{TH}$ therapy in the HIE case with persistent pulmonary hypertension (PPHN). They have regarded PPHN as one of exclusion criteria of TH therapy since there have been a few reports that PPHN cases with moderate to severe HIE cases could undergo TH therapy safely. However, we have experienced six PPHN cases with moderate to severe HIE who could undergo TH therapy safely combined with inhaled nitric oxide (iNO) therapy. We need to clarify what condition is necessary to undergo TH therapy safely combined with iNO therapy for moderate to severe HIE with PPHN.

\section{Objective}

To clarify whether PPHN is exclusion criteria of TH therapy or not. We studied about seven cases with neonatal moderate to severe HIE using TH therapy combined with iNO therapy.

\section{Method \\ Hypothermia criteria were met if infants had cord or first postnatal hour blood gas results with PH 7.0 or base deficit -16 . Infants, if they}

showed either Apgar score at 10 minutes of 5 or need for resuscitation (positive airway pressure or intubation) initiated at birth and continued for 10 minutes, were eligible. Then infants, if they showed symptoms of moderate to severe HIE (Sarnat score 2), were eligible.

\section{Criteria for TH therapy at our institution}

A) over 35 weeks gestational age

pH 7.0 in cord or first postnatal hour blood gas

Base deficit -16 in cord or first postnatal hour blood gas

Apgar score at 10 minutes of 5

need for resuscitation (positive airway pressure or intubation) initiated at birth and continued for 10 minutes

At least one in A

B ) Symptoms of moderate to severe HIE (Sarnat score 2)

Used selective head cooling since 2002 to 2011

Using whole body cooling since 2012.

C) Exclusive criteria

With major anomaly

Hemorrhagic diathesis

With uncontrollable PPHN

\section{Criteria for using NO therapy at our institution}

Diagnosis of PPHN

Hypoxia using $100 \%$ oxygen

Findings by echocardiography 
Citation: Kobata K, Nabetani M, Yutaka N, Hiroyuki, Sanno (2015) Experiences of Therapeutic Hypothermia Therapy on Six Cases with Persistent: Pulmonary Hypertension and Moderate to Severe Hypoxic Ischemic Encephalopathy using Inhaled Nitric Oxide Therapy. J Neonatal Biol 4: 198. doi:10.4172/2167-0897.1000198

Page 2 of 3

From right to left shunt at oval hole or ductus arteriosus.

Flattening of ventricular septum.

Tricuspid regurgitation

AT/ET of pulmonary artery $<0.25$

If PPHN would not be improved by iNO therapy only, we added PGI2, PDE3 inhibitor or nitroglycerin with iNO therapy.

We have not evaluated with tissue Doppeler.

MRI findings classifications around one year old age. normal-mildnormal or partial abnormal signal lesions moderate; two or three partial abnormal signal lesions severealmost of all abnormal lesions

\begin{tabular}{|c|c|c|c|}
\hline & $\begin{array}{l}\text { (T.iNO) } \\
\text { group (n.6) }\end{array}$ & $\begin{array}{l}\text { TH } \\
(n=38)\end{array}$ & $P$ value \\
\hline Gestational weeks & $39.0 \pm 0.8$ & $39.1 \pm 1.6$ & NS \\
\hline Birth weights(g) & $3012 \pm 211$ & $3002 \pm 454$ & NS \\
\hline Apgar (1min) & $1.0 \pm 0.4$ & $2.4 \pm 1.8$ & NS \\
\hline Apgar (5min) & $2.8 \pm 0.7$ & $3.8 \pm 1.9$ & NS \\
\hline $\mathrm{pH}$ tested at admission & $6.94 \pm 0.16$ & $7.04 \pm 0.19$ & NS \\
\hline $\mathrm{BE}(\mathrm{mmo1} / 1)$ at admission & $-12 \pm 11.6$ & $-15.6 \pm 7.1$ & NS \\
\hline
\end{tabular}

Table 1: Comparison between ( $\mathrm{TH}+\mathrm{iNO})$ group and $\mathrm{TH}$ group.

\begin{tabular}{|c|c|c|c|c|c|c|c|}
\hline Case & $\begin{array}{l}\text { Underlying } \\
\text { condition }\end{array}$ & Gestational week & Birth weights (g) & Apgar (1) & Apgar (5) & Apgar (10) & Vasodilators \\
\hline 1 & MAS & $41 / 6$ & 3132 & 3 & 5 & 7 & \\
\hline 2 & NRFS & $39 / 2$ & 2746 & 1 & 1 & & NTG \\
\hline 3 & NRFS & $40 / 0$ & 2776 & 3 & 5 & & $\begin{array}{c}\mathrm{PDE}_{3} \text { inhivitor } \\
\mathrm{PGI}_{2}\end{array}$ \\
\hline 4 & MAS & $42 / 0$ & 4158 & 3 & 5 & & \\
\hline 5 & NRFS & $36 / 1$ & 2660 & 0 & 1 & 4 & $\begin{array}{c}\mathrm{PDE}_{3} \text { inhivitor } \\
\mathrm{PGI}_{2}\end{array}$ \\
\hline 6 & NRFS & $40 / 6$ & 3320 & 2 & 3 & 4 & \\
\hline
\end{tabular}

Table 2: Six cases with PPHN using iNO therapy and TH.

\section{Result}

Between 2002 January and 2014 April at Yodogawa Christian hospital Japan, 48 cases who underwent TH therapy were enrolled. We excluded 3 cases not suitable to criteria for TH therapy (one died, and two mild HIE). We experienced 7 PPHN cases who needed TH therapy in accordance with introducing criteria at our hospital. We stopped TH therapy in the one PPHN case because he showed brain death and we judge he could not gain the benefit from TH therapy. In this case, we had not experienced circulatory and respiratory deterioration. We have experienced six PPHN cases who underwent TH therapy safely and completely combined with iNO therapy. No case showed methemogulobinemia or cerebral hemorrhage during $\mathrm{TH}$ and iNO therapy in these seven cases. All cases needed to take vasopressor drugs.

We have compared these factors such as gestational age, Apgar score (1 min), Apgar score (10 min), another combined therapy, MRI findings around one-year-old, Gross Motor Function Classification System (GMFCS), and developmental quotient around one and a half year old between two groups, ( $\mathrm{TH}$ group ; 38 cases) and (TH+iNO group; 6 cases).

In TH group, gestational age was $39.1 \pm 1.6$ weeksbirth weights was $3002 \pm 454 \mathrm{~g}$ Apgar score $(1 \mathrm{~min})$ was $2.4 \pm 1.8$ and Apgar score (5 min) was $3.8 \pm 1.9$ mean $\pm \mathrm{SD})$. On the other hands, in (TH $+\mathrm{iNOgroup}$, gestational age was $39.0 \pm 0.8$ weeksbirth weights was
$3012 \pm 211 \mathrm{~g}$ APGAR score $(1 \mathrm{~min})$ was $1.0 \pm 0.4$ and Apgar score (5 min) was $2.8 \pm 0.7$ mean $\pm \mathrm{SD}$ ) (Table 1 ). There are no significant differences of these perinatal factors. All of six cases have used vasoactive agoniststhree of six cases have used vasodilators (Table 2). There was no side effect by vasodailators including $\mathrm{PGI}_{2}$ all of six cases had succeeded to recover from PPHN condition. MRI findings around one year old age showed severe findings (one total necrosis of cerebral lesion and one basal ganglia and thalamic lesion), moderate findings (two periventricular lesion) and mild or no findings(one subependymal hemorrhage lesion). Between $\mathrm{TH}$ group and ( $\mathrm{TH}+\mathrm{iNO})$ group, the rate of cases with severe brain damage is almost the same (Chart 1).
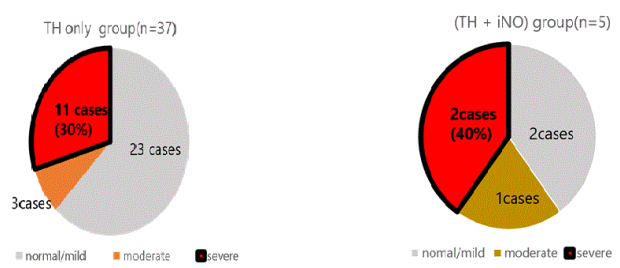

Chart 1: Brain MRI findings at one year old. 
Citation: Kobata K, Nabetani M, Yutaka N, Hiroyuki, Sanno (2015) Experiences of Therapeutic Hypothermia Therapy on Six Cases with Persistent: Pulmonary Hypertension and Moderate to Severe Hypoxic Ischemic Encephalopathy using Inhaled Nitric Oxide Therapy. J Neonatal Biol 4: 198. doi:10.4172/2167-0897.1000198

Page 3 of 3

There are no significant differences of GMFCS, and developmental quotient around one and a half year old between $(\mathrm{TH}+\mathrm{iNO})$ group and TH group (Chart 2 and 3).

\section{Discussion}

We could show the possibility to undertake TH therapy safely for new-borns with HIE and PPHN during iNO therapy, if we could maintain intensive respiratory and cardiac support carefully. Even in the most severe brain condition, TH therapy did not deteriorate circulatory and respiratory condition. We need multi-centered investigations to clarify more precise entry criteria and exclusion criteria of $\mathrm{TH}$ therapy for new-borns with moderate to severe HIE during iNO therapy.

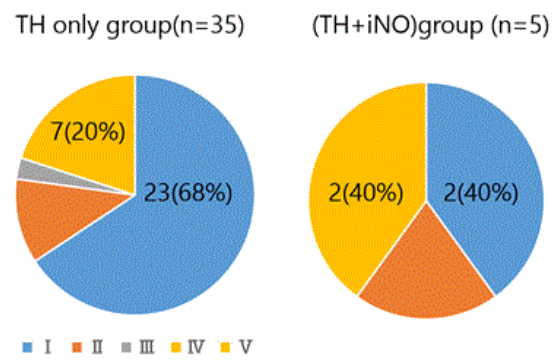

Chart 2: GMFCS at one-half-year-old.

Many studies reported that nitric oxide is raised at brain cells during HIE insult [2]. Effect of iNO on neural system is controversial [3]. We consider that nitric oxide inhaled dose not influence on neural cells, because nitric oxide taken into vascular by iNO therapy is very shortterm half-life in blood. Kida et al. showed beneficial effect of iNO in Cardiovascular Pulmonary Resuscitation (CPR) and Cardiac Arrest (CA) model mice [4]. In their experimental study, the sooner CPR/CA model mice were used iNO, the higher those each percent survival were for brain MRI, signals (of T2 weighted) of basal ganglia were lower that of $\mathrm{TH}$ alone mouse than that of $\mathrm{TH}$ combined iNO mouse. They suggested NO synthase 3 is required for the beneficial effects of TH. And NO breathing exerts protective effects after CA/CPR even when $\mathrm{TH}$ is not effective due to impaired endogenous nitric oxide production. This suggestion showed good accordance with our result

that TH is capable to undergo safely with iNO therapy for HIE cases with PPHN. And TH might be favourable effect in addition to nitric oxide for neurological prognosis.

Our study was limited by the lack of cases. So we couldn't get results as primary data. In addition, there were two methods of TH mixed in our study, such as whole body cooling and selective head cooling. We should arrange the method of $\mathrm{TH}$ as far as possible and gather more cases.

However, there have been still a few reports that HIE cases have been used $\mathrm{TH}$ and $\mathrm{NO}$ together and that effects of NO combined with TH to neural cells are analysed by molecular methods. We need also further experimental studies to clarify pathogenesis.

TH only group $(n=37)$

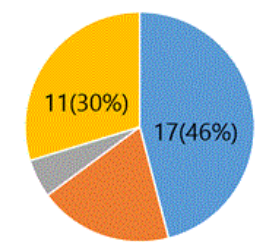

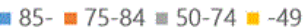

$(\mathrm{TH}+\mathrm{iNO})$ group $(\mathrm{n}=4)$

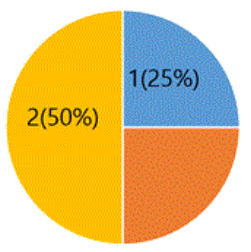

Chart 3: Developmental quotient at one-half-year-old.

\section{References}

1. Periman JM, Wyllie J, Atkins DL (2010) Neonatal resuscitation: 2010 International Consensus on Cardiop pulmonary Resucitation and Emergency Cardiovascular Care Science With Treatment Recommendations. Ciculation 122: S516-S538.

2. Cilio MR, Ferriero DM (2010) Synergistic neuroprotective therapies with hypothermia. Semin Fetal Neonatal Med 15: 293-298.

3. Faraci FM, Brian JE Jr (1994) Nitric oxide and the cerebral circulation. Stroke 25: 692-703.

4. Kida K, Shirozu K, Yu B, Mandeville JB, Bloch KD, et al. (2014) Beneficial effects of nitric oxide on outcomes after cardiac arrest and cardiopulmonary resuscitation in hypothermia-treated mice. Anesthesiology 120: 880-889. 